\title{
One-Step Cohydrothermal Synthesis of Nitrogen-Doped Titanium Oxide Nanotubes with Enhanced Visible Light Photocatalytic Activity
}

\author{
Cheng-Ching Hu, ${ }^{1}$ Tzu-Chien Hsu, ${ }^{1}$ and Li-Heng Kao ${ }^{2}$ \\ ${ }^{1}$ Department of Materials and Optoelectronic Science, National Sun Yat-Sen University, Kaohsiung 80424, Taiwan \\ ${ }^{2}$ Department of Chemical and Materials Engineering, National Kaohsiung University of Applied Science, Kaohsiung 80778, Taiwan
}

Correspondence should be addressed to Tzu-Chien Hsu, tjhsu@facmail.nsysu.edu.tw

Received 15 July 2011; Revised 7 September 2011; Accepted 8 September 2011

Academic Editor: Jae Sung Lee

Copyright (C) 2012 Cheng-Ching Hu et al. This is an open access article distributed under the Creative Commons Attribution License, which permits unrestricted use, distribution, and reproduction in any medium, provided the original work is properly cited.

\begin{abstract}
Nitrogen-doped $\mathrm{TiO}_{2}$ nanotubes with enhanced visible light photocatalytic activity have been synthesized using commercial titania P25 as raw material by a facile P25/urea cohydrothermal method. Morphological and microstructural characteristics were conducted by transmission electron microscopy, powder X-ray diffraction, and nitrogen adsorption/desorption isotherms; chemical identifications were performed using X-ray photoelectron spectroscopy, and the interstitial nitrogen linkage to the $\mathrm{TiO}_{2}$ nanotubes is identified. The photocatalytic activity of nitrogen-doped $\mathrm{TiO}_{2}$ nanotubes, evaluated by the decomposition of rhodamine B dye solution under visible light using UV-vis absorption spectroscopy, is found to exhibit $\sim$ four times higher than that of P25 and undoped titanate nanotubes. Factors affecting the photocatalytic activity are analyzed; it is found that the nitrogen content and surface area, rather than the crystallinity, are more crucial in affecting the photocatalytic efficiency of the nitrogen-doped $\mathrm{TiO}_{2}$ nanotubes.
\end{abstract}

\section{Introduction}

Titanium oxide $\left(\mathrm{TiO}_{2}\right)$ is one of the well-known photocatalysts with many promising properties such as nontoxicity, excellent chemical stability, high photocatalytic activity, high resistance to photocorrosion, and great photostability. The good semiconductor characteristics of $\mathrm{TiO}_{2}$ render itself wilder applications, especially in the photoelectrochemical devices. They have been applied to the decomposition of some pollutants under light irradiation, such as nitrogen monoxide in atmosphere and organic pollutants in water. However, applications of pure titania suffer from limitation to only UV light $(\lambda<380 \mathrm{~nm})$ because of its wide band gap value of $3.2 \mathrm{eV}$. Since UV light accounts for only a small fraction $(4 \sim 5 \%)$ of the natural sun light as compared to visible light $(45 \%)$, any shift in the optical response of $\mathrm{TiO}_{2}$ from UV to visible spectral range will have a profound positive effect on its photocatalytic efficiency [1-4].
There are two basic strategies to overcome the limitation and to improve the efficiency of photocatalysis. One is enlarging the light absorption range of the photocatalysts to enhance the harvesting efficiency of sun light by doping metal or nonmetal ions. The second one is the control of the morphology and size of the particles and their distribution, phase composition, and porosity of the photocatalyst. Early attempts on the shifting of $\mathrm{TiO}_{2}$ absorption into visible light region mainly focus on the doping with transition metals [5-7]. But it suffers from thermally instability, its tendency to form charge carrier recombination centers $[6,8]$, and the expensive ion implantation facilities; all these make metaldoped $\mathrm{TiO}_{2}$ impractical.

Efforts have been made to modify titanium dioxide with nonmetal elements such as boron, carbon, sulfur, fluorine, and nitrogen $[2,4,9-11]$ to efficiently extend the photoresponse from UV to visible light region. Asahi et al. showed an effective shift to visible light region by doping with nitrogen 
[2]. The reason for the improvement of photocatalytic activity has been often attributed to the decrease of the band gap, which is due to either mixing the $\mathrm{N} 2 \mathrm{p}$ states with $\mathrm{O} 2 \mathrm{p}$ states on the top of valence band, or the creation of an ioninduced mid-gap level.

Beside metal and nonmetal doping method, it is well known that the performance of $\mathrm{TiO}_{2}$ depends strongly on its crystallite phase, size, and morphology, since they give an important influence on the chemical and physical properties of $\mathrm{TiO}_{2}$. Kasuga et al. $[12,13]$ reported that the thermal treatment of $\mathrm{TiO}_{2}$ particles in $\mathrm{NaOH}$ resulted in the formation of $\mathrm{TiO}_{2}$ nanotubes with large surface areas. On the other hand, one-dimensional nanostructured $\mathrm{TiO}_{2}$, such as nanotubes and nanofibers, are of particular significance due to their superior electronic, magnetic, optical, catalytic, and mechanical properties, and their potential applications in environmental purification, gas sensors, and solar cell [1416].

$\mathrm{N}$-doped $\mathrm{TiO}_{2}$ has been prepared by various methods such as mechanochemical reaction [17], sputtering [18], ion implantation [19], chemical vapor deposition [20], and sol-gel processing $[21,22]$. Most of the preparation methods adopted $\mathrm{NH}_{3}$ under higher temperatures as the nitrogen source, which did not meet the ever-increasing environmental restrictions and energy-saving requirement; other methods such as ion implanter or complex process were either complicated or expensive $[23,24]$. Therefore, it is a worthwhile effort to find a simple and low-temperature approach to synthesize $\mathrm{N}$-doped $\mathrm{TiO}_{2}$ nanotubes without destroying their inherent tubular morphology and keep their superior photocatalytic property to extend the application of the $\mathrm{N}$-doped $\mathrm{TiO}_{2}$ photocatalysts. In this study, $\mathrm{N}$-doped $\mathrm{TiO}_{2}$ nanotubes are synthesized via a facile cohydrothermal process. This unique process combines the chemical vapor deposition of urea as the nitrogen source and the alkaline hydrothermal treatment of $10 \mathrm{M} \mathrm{NaOH}$ at the same time, combining the nitrogen-doping and $\mathrm{TiO}_{2}$ nanotube synthesis in a single process. The effects of calcination temperature and nitrogen content on the microstructure of the nanotubes are investigated in detail. The photocatalytic activity of Ndoped $\mathrm{TiO}_{2}$ nanotubes is evaluated by the photocatalytic degradation of rhodamine $\mathrm{B}(\mathrm{RB})$ dye solution under visible light irradiation.

\section{Experimental}

2.1. Preparation of $\mathrm{N}$-Doped $\mathrm{TiO}_{2}$ Nanotubes. Titanium dioxide used for synthesis of the nanotubes was a commercially available $\mathrm{P} 25 \mathrm{TiO}_{2}$ powder (P25, Acros), consisting of about $30 \%$ rutile and $70 \%$ anatase with a primary particle size of about $21 \mathrm{~nm}$; it was used without further treatment. Urea was purchased from Soha Co. Ltd. and used as the nitrogen source. All other reagents were of analytical grade, and all the water used was deionized.

$\mathrm{TiO}_{2}$ nanotubes were synthesized by a hydrothermal method analogous to the one proposed by Kasuga et al. [12]. $1.5 \mathrm{~g} \mathrm{P} 25 \mathrm{TiO}_{2}$ powder was dispersed in $50 \mathrm{~mL} \mathrm{NaOH}$ solution with a concentration of $10 \mathrm{molL}^{-1}$ and stirred for
$30 \mathrm{~min}$. Then, a certain amount of urea was added and stirred for another $30 \mathrm{~min}$. The solution was heated at $110^{\circ} \mathrm{C}$ for $24 \mathrm{~h}$ under hydrothermal condition in a PTFE-lined stainless steel vessel. It was then filtered and washed with $0.1 \mathrm{~N} \mathrm{HCl}$ solutions until $\mathrm{pH}<7$, followed by washing with DI water and drying at $80^{\circ} \mathrm{C}$ in air overnight. Samples with different urea loadings $(0,1.9 \mathrm{~g})$ are designated as TC- 0 and TC1. Sample TC-1 was calcined under various temperatures ranging from $200^{\circ} \mathrm{C}$ to $400^{\circ} \mathrm{C}$.

2.2. Characterizations. X-ray diffraction patterns were collected on a Siemens D5000 powder diffraction system equipped with a position-sensitive detector, using $\mathrm{Cu} \mathrm{K} \alpha(\lambda=$ $0.154 \mathrm{~nm}$ ) radiation under $40 \mathrm{kV}$ working voltage and $30 \mathrm{~mA}$ working current. The patterns were collected in the range of $2 \theta=5-80^{\circ}$ with a speed of $1.5^{\circ} / \mathrm{min}$ in the continuous scan mode. Nitrogen physisorption was performed at $-196^{\circ} \mathrm{C}$ with a Micromeritics ASAP 2010 apparatus. Prior to the measurements, the powdered samples were degassed for $24 \mathrm{~h}$ at $200^{\circ} \mathrm{C}$ in vacuum. Surface area, pore volume, and pore size distribution were determined with standard BET and $\mathrm{BJH}$ methods, respectively. Samples ultrasonicated and filtered on holey carbon grids were examined by the transmission electron microscopy (TEM, JEOL AEM 3010, Tokyo, Japan) operating at $200 \mathrm{kV}$. The chemical nature of $\mathrm{N}$ in $\mathrm{TiO}_{2-x} \mathrm{~N}_{x}$ was studied using X-ray photoelectron spectroscopy (XPS) by a Krato Axis Ultra DLD (delay line detector) with $\mathrm{Al} \mathrm{K \alpha}$ radiation as the exciting source. All the binding energy was referenced to the $\mathrm{C} 1 \mathrm{~s}$ peak at $285 \mathrm{eV}$ of the surface carbon for calibration.

2.3. Photocatalytic Activity. The photocatalytic activity of the as-prepared samples was evaluated by the photodegradation of rhodamine $\mathrm{B}$ dye $(\mathrm{RB})$ under a $500 \mathrm{~W}$ xenon lamp through a cutoff filter (UVCUT425, $\lambda>400 \mathrm{~nm}$, Rocoes). The mixture containing the $\mathrm{N}$-doped $\mathrm{TiO}_{2}$ nanotubes $(50 \mathrm{mg})$ and $\mathrm{RB}(7.5 \mathrm{mg} / \mathrm{L}, 100 \mathrm{~mL})$ was magnetically stirred in a $250 \mathrm{~mL}$ beaker for $1 \mathrm{~h}$ in darkness to reach adsorption equilibrium before irradiation. At the given time intervals during the irradiation period, samples were taken from the suspension and immediately centrifuged for $20 \mathrm{~min}$. After recovering the catalyst by centrifugation, the absorbance of the clear solution was measured by using a UV-vis spectrophotometer (Hitachi U-1500) at $554 \mathrm{~nm}$ ( $\lambda_{\max }$ for RB). For comparison, the photocatalytic activity of pure $\mathrm{P} 25$ and the undoped $\mathrm{TiO}_{2}$ nanotubes was also performed. The UV-vis light absorption spectra were obtained from a spectrophotometer (Hitachi U4100) equipped with an integrating sphere assembly, using the diffuse reflection method and $\mathrm{BaSO}_{4}$ as a reference.

\section{Results and Discussion}

3.1. Morphological and Microstructural Characterizations of $\mathrm{N}$-Doped $\mathrm{TiO}_{2}$ Nanotubes. The purpose of adding urea is to provide nitrogen source during the synthesis process of $\mathrm{TiO}_{2}$ nanotube. Urea is a very weak Brønsted base, highly soluble in water, and its hydrolyzing rate may be controlled by temperature, its decomposition giving rise to ammonium 
carbonate, and when the temperature is above $90^{\circ} \mathrm{C}$, it obviously begins to hydrolyze in a basic solution and can be described by:

$$
\mathrm{CO}\left(\mathrm{NH}_{2}\right)_{2}+2 \mathrm{H}_{2} \mathrm{O} \longrightarrow 2 \mathrm{NH}_{4}{ }^{+}+\mathrm{CO}_{3}{ }^{2-}
$$

TEM image of the as-prepared $\mathrm{TiO}_{2}$ nanotubes shown in Figure 1(a) reveals a large amount of nanotubes with an outer diameter of $8-15 \mathrm{~nm}$ and a length of several hundred nanometers. HRTEM image in Figure 2(a) indicates that the as-prepared $\mathrm{N}$-doped $\mathrm{TiO}_{2}$ nanotubes possess rather uniform inner and outer diameters along their length.

A closer observation further suggests that the nanotubes are multilayered and open-ended, in good agreement with the previous reports $[14,25]$. As shown in Figure 1(b), after calcination at $400^{\circ} \mathrm{C}$, some of the nanotubes with porous multilayer structure become dense and aggregated to form nanorods with a diameter of $8-15 \mathrm{~nm}$ and a length of several hundred nanometer, also in agreement with the previous report [26]; other nanotubes begin to form particles.

HRTEM in Figure 2(b) for calcined $\mathrm{TiO}_{2}$ nanotube TC$1(400)$ (the number in parenthesis indicates that sample was calcined at $400^{\circ} \mathrm{C}$ ) suggests that the crystalline structure of the nanorods is of anatase phase. The interplanar spacing of the nanorods is measured to be ca. $0.35 \mathrm{~nm}$, corresponding to the (101) crystal plane of anatase. Selected area electron diffraction pattern (inset, Figure 2(b)) reveals that five indiscernible diffraction rings can be identified as (101), (004), (200), (211), and (204); all belong to the anatase phase of the $\mathrm{TiO}_{2}$ crystal.

Figure 3 shows the XRD patterns of the titanate nanotubes TC- 1 calcined at $200^{\circ} \mathrm{C}-400^{\circ} \mathrm{C}$, along with the starting material P25 for comparison. For the as-prepared sample, there exists three broad yet weak peaks at $2 \theta=$ $24.5^{\circ}, 28.2^{\circ}$, and $48.4^{\circ}$, corresponding to (110), (130), and (200) reflections, respectively. This suggests a rather low crystallinity of the as-prepared TC- 1 . In addition, the broad peak at $2 \theta=9.6 \sim 13^{\circ}$ can be assigned to the different interlayer spacings of the nanotubes having the trititanate configuration $(\mathrm{H}, \mathrm{Na})_{2} \mathrm{Ti}_{3} \mathrm{O}_{7}$ [27]. They can be ascribed to the lepidocrocite-type sodium titanate compounds [27-29]. As reported, this sodium titanate is probably first formed from original titania powder through hydrothermal treatment and then changes to hydrogen titanate after washing with $\mathrm{HCl}$ solution through an ion-exchange mechanism [29]. Several crystal structures of the $\mathrm{TiO}_{2}$ derived titanates have been reported, including $\mathrm{H}_{2} \mathrm{Ti}_{3} \mathrm{O}_{7}$ (or $\mathrm{Na}_{2} \mathrm{Ti}_{3} \mathrm{O}_{7}$ ), $\mathrm{Na}_{x} \mathrm{H}_{2-x} \mathrm{Ti}_{3} \mathrm{O}_{7}, \quad \mathrm{Na}_{2} \mathrm{Ti}_{2} \mathrm{O}_{4}(\mathrm{OH})_{2}, \quad$ or $\mathrm{Na}_{y} \mathrm{H}_{2-y} \mathrm{Ti}_{n} \mathrm{O}_{2 n+1 \cdot x} \mathrm{H}_{2} \mathrm{O}$ [30], where $x$ and $y$ depend strongly on the $\mathrm{pH}$ value of the acidic washing solution during the postcalcination treatment.

As the calcination temperature further increases, those peaks belonging to lepidocrocite-type sodium titanate phase disappear gradually, and the anatase phase of (101), (004), (200), and (211) reflections becomes the main crystal form. Meanwhile, the peak located at ca. $12^{\circ}$ (nanotubes) was weakened moderately, accompanying with the formation of anatase phase. This indicates a decrease of the interlayer spacing due mainly to the dehydration of the interlayered
$\mathrm{OH}$ groups, while the titanate structure remains almost unchanged. It has been reported that for titanate nanotubes with the postheat treatment above $350^{\circ} \mathrm{C}$, some of the nanotubes began to break into particles of anatase phase, and the others remained as nanotubes. The remaining nanotubes was believed to be stabilized by the remnant $\mathrm{Na}$ atoms [27]. Our XRD results demonstrate that the crystallinity of the resultant nanotubes increases with increasing heattreatment temperatures. The diffraction peaks of the samples TC-1(400) can be indexed as the anatase phase of $\mathrm{TiO}_{2}$. (JCPDS 21-1272). No nitrogen-derived peaks are detected, presumably due to the fact that the content of $\mathrm{N}$ doping is very low and the doped $\mathrm{N}$ is uniformly distributed in the nanotubes. It can be concluded that $\mathrm{N}$ doping does not cause the change in crystallite structure of $\mathrm{TiO}_{2}$, which was consistent with previous report [31].

From the nitrogen physisorption, the adsorptiondesorption isotherm of TC- 1 shown in Figure 4 is the type IV isotherm with $\mathrm{H} 1$ hysteresis, according to IUPAC classification [32]. The shapes of hysteresis loops have often been identified with specific pore structures. Thus, Type H1 hysteresis appearing in the multilayer range of physisorption isotherms is usually associated with capillary condensation in mesopore structures. As expected, the as-prepared titanate nanotubes have a large mesopore volume of $1.01 \mathrm{~cm}^{3} / \mathrm{g}$. The BJH method was employed to analyze the pore size distributions, and the results are depicted in the inset of Figure 4. The pore structures of TC- 1 samples determined according to the adsorption data are also collected in Table 1. The distributions are relatively narrow within $15 \mathrm{~nm}$. We infer that both tips of nanotubes are opened and their inner cavities are accessible to $\mathrm{N}_{2}$ gas molecules. Therefore, the enhancement of pore volume can be mainly contributed by the tubular-type titanate. This type of mesoporous $\mathrm{TiO}_{2}$ is credited to show an excellent performance in photocatalysis and photovoltaic applications.

As compared to the as-prepared one, the specific surface areas of TC-1(400) decreased rapidly from 292 to $73 \mathrm{~m}^{2} / \mathrm{g}$, pore volume reduced from 1.01 to $0.57 \mathrm{~cm}^{3} / \mathrm{g}$, and the pore size distribution extended from 15.0 to $31.8 \mathrm{~nm}$. All these could be inferred to the substantial destruction of interlayer structure in nanotubes and the formation of particles with smaller specific surface areas. The results of reduced specific surface area are in good agreement with those of the XRD and TEM observations from this study.

3.2. Chemical Identification of $\mathrm{N}$-Doped $\mathrm{TiO}_{2}$ Nanotubes. XPS was conducted for chemical identification of the valence state of the doping nitrogen in detail. Figure 5 shows that the XPS survey spectrum of the nitrogen-doped titanate nanotubes $\mathrm{TC}-1$, revealing strong peaks of $\mathrm{Ti}, \mathrm{O}$, and $\mathrm{C}$ elements. The minor peak at about $400 \mathrm{eV}$ can be assigned to the binding energy of $\mathrm{N} 1 \mathrm{~s}$. The $\mathrm{C}$ element can be ascribed to the adventitious hydrocarbon in carbon tape from XPS instrument itself. Table 2 summarizes the XPS spectra of TC0 , TC-1, and TC-1(400).

The high-resolution XPS spectra of the $\mathrm{N} 1 \mathrm{~s}$ region on the surface of TC-0, TC- 1 , and TC-1(400) are displayed 


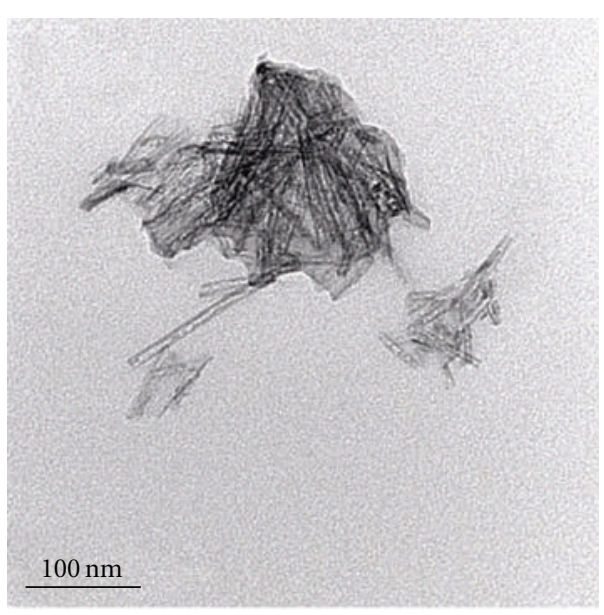

(a)

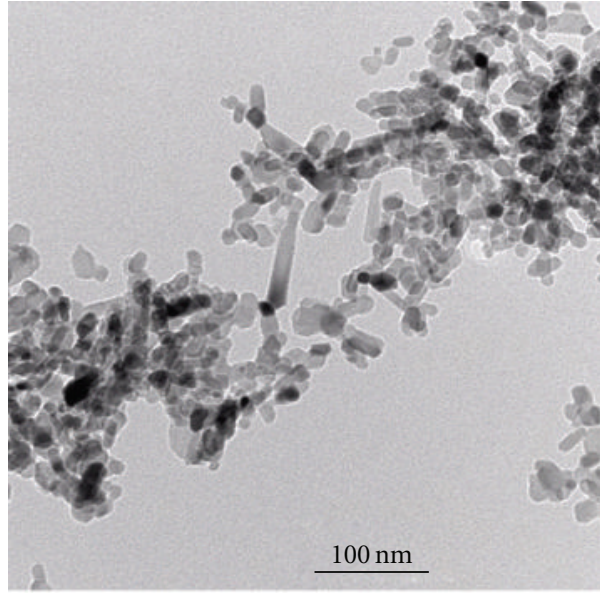

(b)

FIgURE 1: TEM images of (a) as-prepared TC-1 and (b) TC-1(400).

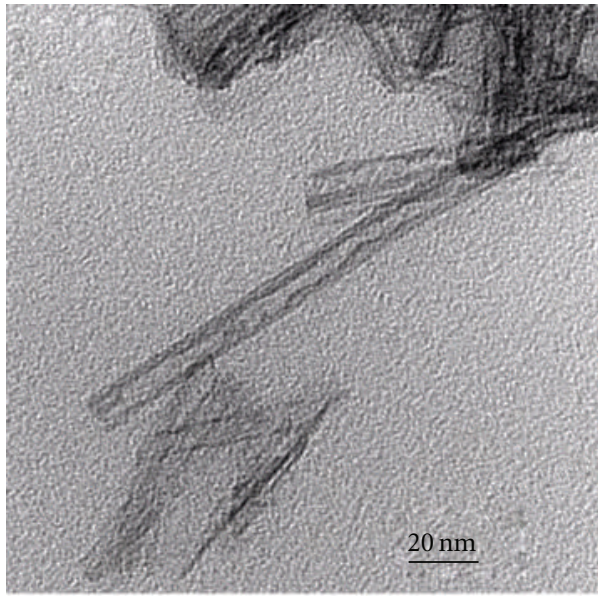

(a)

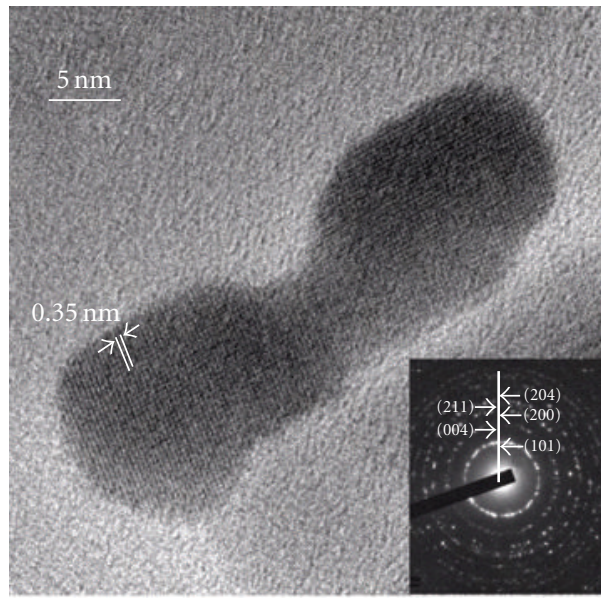

(b)

FIgURE 2: HRTEM images of (a) as-prepared TC-1 and (b) TC-1(400).

in Figure 6, from which the nitrogen concentrations are estimated to be about $0.50 \%, 2.69 \%$, and $2.46 \%$ for TC- 0 , TC-1, and TC-1(400), respectively. The low nitrogen content of the undoped TC- 0 might be due to the existence of the molecularly chemisorbed $\gamma$-N, which should not be ignored. Sample TC- 1 shows a single peak at $400.6 \mathrm{eV}$ for N 1s core level. The assignment of the XPS peak of $\mathrm{N}$ 1s has still been under disputation, and some controversial hypotheses have been provided. Some reports suggested that the $\mathrm{N} 1 \mathrm{~s}$ peak at $399-400 \mathrm{eV}$ is due to the $\mathrm{NH}_{3}$ adsorbed on the $\mathrm{TiO}_{2}$ surface $[2,33]$. Other researchers pointed out that the presence of oxidized nitrogen such as $\mathrm{Ti}-\mathrm{O}-\mathrm{N}$ or $\mathrm{Ti}-\mathrm{N}-\mathrm{O}$ linkages should appear above $400 \mathrm{eV}$ [34-36]. In most cases, the $\mathrm{N}$ 1s peaks at around $400 \mathrm{eV}$ has been assigned to the molecularly chemisorbed $\gamma-\mathrm{N}$ [37]. Although not proven experimentally, it has been postulated that the bonding energy of $\mathrm{N} 1 \mathrm{~s}$ is higher when the nitrogen atom in a chemical linkage shows more positive formal charge $[34,36]$. Therefore, the $\mathrm{N} 1 \mathrm{~s}$ peak at $400 \mathrm{eV}$ in this study is ascribed to a characteristic peak of interstitial $\mathrm{N}$, which is hosted in an interstitial position and directly bound to lattice oxygen. In this study, urea was used as nitrogen source and contained in cohydrothermal synthesis process, it is highly soluble in water, and its controlled hydrolysis in aqueous solutions can yield ammonium cyanate or its ionic form $\left(\mathrm{NH}_{4}{ }^{+}, \mathrm{NCO}^{-}\right)$ [38]. From these viewpoints, the $\mathrm{N} 1 \mathrm{~s}$ peak explored in this work can be assigned to the anionic $\mathrm{N}^{-}$in Ti-O-N or Ti-NO linkages. In Figure 6, the N 1s peak of TC-1(400) centering at $399.9 \mathrm{eV}$ has a lower $\mathrm{N}$ concentration. This low $\mathrm{N}$ content may be due to the replacement of $\mathrm{N}$ in the matrix by $\mathrm{O}$ during the annealing process.

The high-resolution XPS spectra of the Ti $2 \mathrm{p}$ and $\mathrm{O}$ 1 s on the surface of TC-1 and TC-1(400) are shown in Figure 7 . Both peaks are significantly reduced in intensity by calcination. It can be seen that peaks of Ti $2 \mathrm{p}_{3 / 2}(459.8 \mathrm{eV})$, Ti $2 \mathrm{p}_{1 / 2}(465.5 \mathrm{eV})$, and $\mathrm{O} 1 \mathrm{~s}(531.1 \mathrm{eV})$ of sample TC1(400) shift to higher binding energy, as compared to those of sample TC-1. This can be attributed to the formation of 


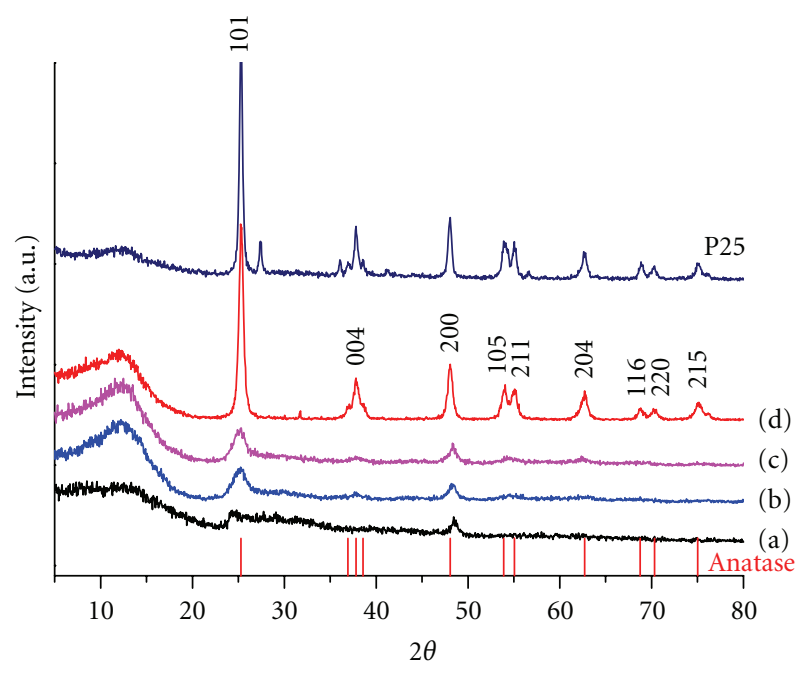

FIgURE 3: XRD patterns of P25 and sample TC-1 calcined at various temperatures; (a) as-prepared, (b) $200^{\circ} \mathrm{C}$, (c) $300^{\circ} \mathrm{C}$, and (d) $400^{\circ} \mathrm{C}$.

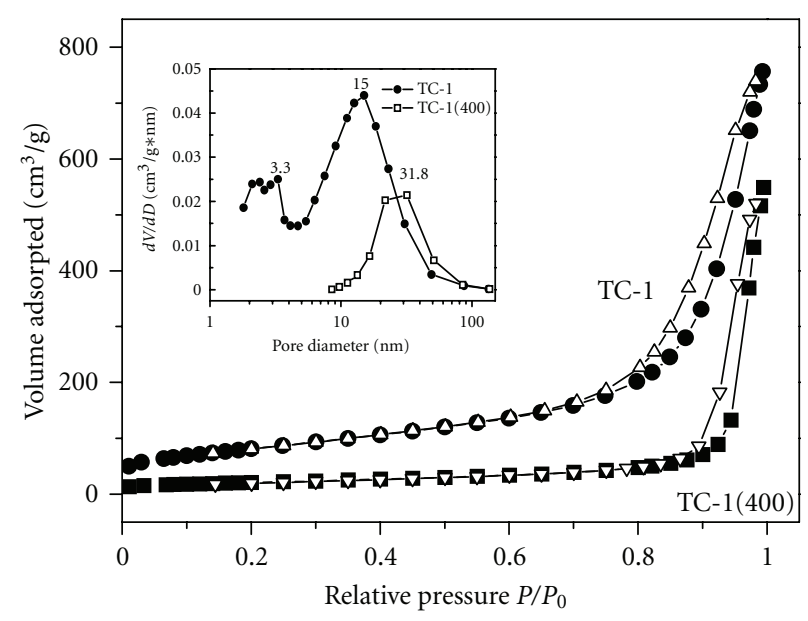

FIGURE 4: Nitrogen adsorption isotherms for as-prepared TC-1 and calcined TC-1(400).

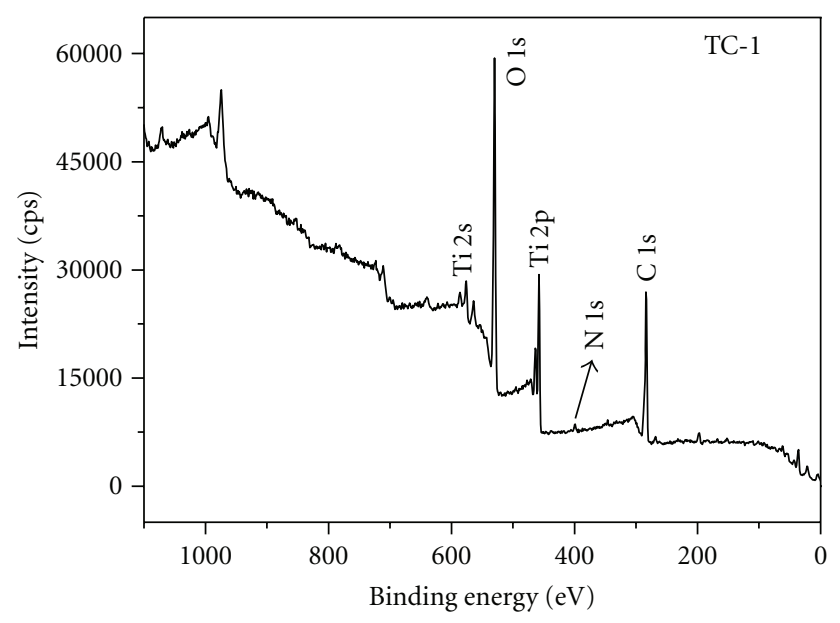

FIGURE 5: XPS survey of TC-1.

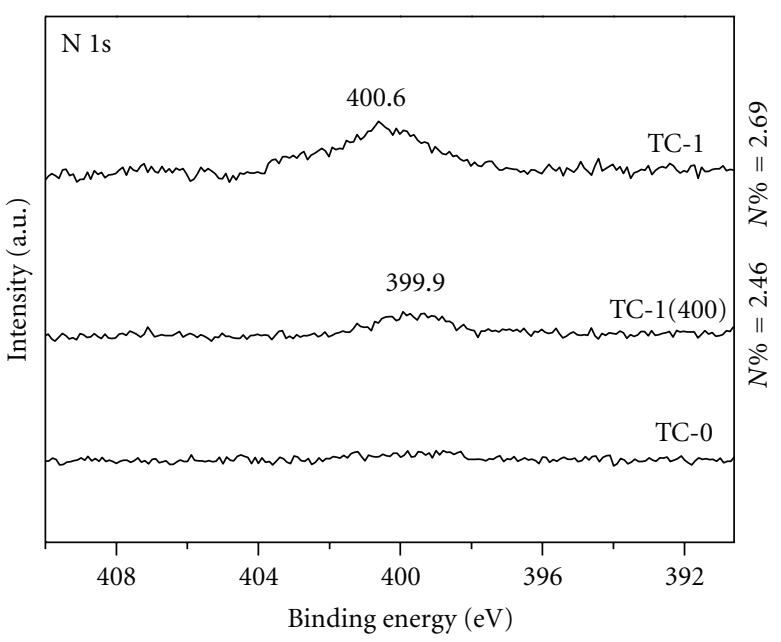

FIgURE 6: XPS N1s spectra of TC-0, nitrogen doped TC-1 and TC$1(400)$.

TABLE 1: Nitrogen physisorption properties of N-doped TC-series.

\begin{tabular}{lcccc}
\hline Sample & Urea $(\mathrm{g})$ & $S_{\text {BET }}\left(\mathrm{m}^{2} / \mathrm{g}\right)^{\mathrm{a}}$ & $D_{\text {BJH-ads }}(\mathrm{nm})^{\mathrm{b}}$ & $V_{\text {Pore }}\left(\mathrm{cm}^{3} / \mathrm{g}\right)^{\mathrm{c}}$ \\
\hline TC-0 & 0.00 & 207 & 9.2 & 0.48 \\
TC-1 & 1.88 & 292 & 15.0 & 1.01 \\
TC-1(400) & 1.88 & 73 & 31.8 & 0.57 \\
\hline
\end{tabular}

${ }^{a}$ BET surface area calculated from the linear part of BET plot.

${ }^{b}$ Estimated using the adsorption branch of the isotherm by BJH method.

'Single-point total pore volume of pores at $P / P_{0}=0.97$.

TABLE 2: XPS of TC-series.

\begin{tabular}{lcccc}
\hline Sample & $\begin{array}{c}\text { Nitrogen content } \\
(\%)^{\mathrm{a}}\end{array}$ & $\begin{array}{c}\mathrm{N} 1 \mathrm{~s} \\
(\mathrm{eV})\end{array}$ & $\begin{array}{c}\mathrm{O} 1 \mathrm{~s} \\
(\mathrm{eV})\end{array}$ & $\begin{array}{c}\mathrm{Ti} 2 \mathrm{p}_{3 / 2} \\
(\mathrm{eV})\end{array}$ \\
\hline TC-0 & 0.50 & 398.0 & 528.0 & 457.0 \\
TC-1 & 2.69 & 400.6 & 530.3 & 458.8 \\
TC-1(400) & 2.46 & 399.9 & 531.1 & 459.8 \\
\hline
\end{tabular}

${ }^{a}$ Nitrogen doping percentage calculated according to the curve fitting of the XPS micrographs for the $\mathrm{N} 1 \mathrm{~s}$ region.

hyponitrite $\left(\mathrm{N}_{2} \mathrm{O}_{2}\right)^{2-}$ in sample TC-1(400) after calcination, supporting further the postulate of the interstitial doping of nitrogen atoms into the lattice in sample TC-1 [31]. These XPS results lead to the confirmation that nitrogen is successfully incorporated into the titania in this study.

A controversial viewpoint on the nitrogen doping mechanism has been proposed, and it was postulated that the nitrogen should be doped into the oxide side of the nanotubes during calcination. Apparently, this is not what found, particularly from a series of XPS data in this work.

The urea adopted is highly soluble in water, and its hydrolyzing rate may be controlled by temperature, giving rise to ammonium carbonate when the autoclave temperature is above $90^{\circ} \mathrm{C}$. Similar urea applications have also been reported. Cong et al. applied urea as nitrogen source in the sol-gel hydrothermal reaction to synthesize $\mathrm{N}$-doped $\mathrm{TiO}_{2}$ successfully [39]. Another study by Peng et al. used P25 and urea in ethanol via a solvothermal approach by 


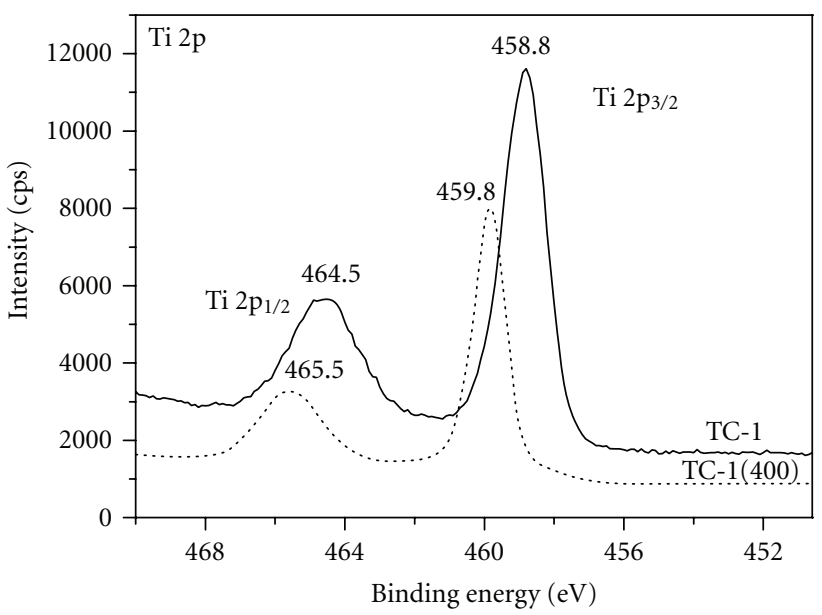

(a)

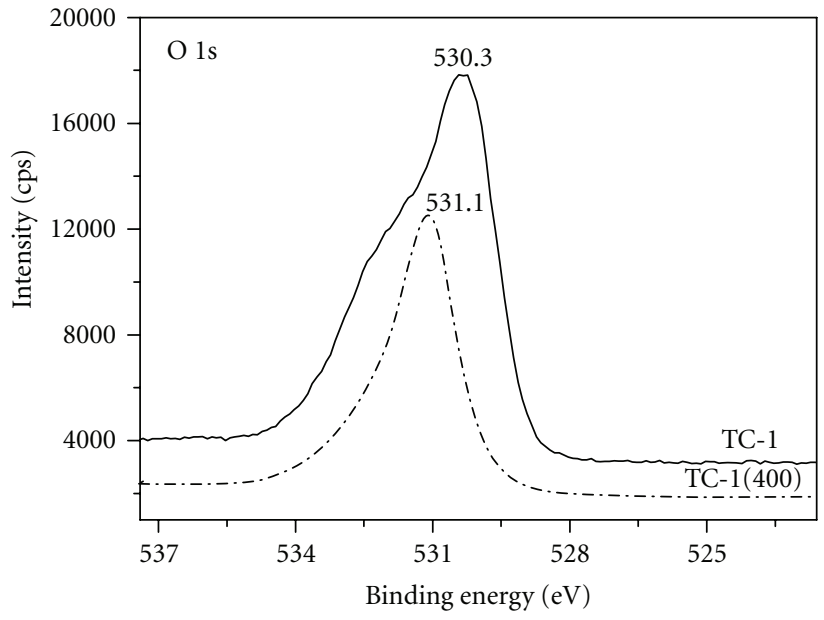

(b)

Figure 7: High-resolution XPS spectra of TC-1 and TC-1(400), (a) Ti 2p (b) O1s.

microwave; the temperature was set above $135^{\circ} \mathrm{C}$, higher than the decomposition temperature of urea. They reported the as-synthesized yellowish powder of nitrogen-doped titanium dioxide possessed the best photocatalytic activity [31]. Although the exact mechanism of urea hydrolysis in autoclave was not clear, it was confirmed by XPS in this study that the as-prepared sample TC-1 has the stronger N1s peak and the higher nitrogen content up to $2.69 \%$. All of these data strongly indicate that nitrogen was directly doped during the one-step cohydrothermal reaction.

3.3. Photocatalytic Activity. The UV-vis diffuse reflectance spectra of samples TC-1, TC-1(400), TC-0, and P25 are shown in Figure 8. Compared with P25, samples TC-1, TC-1(400), and TC-0 present a noticeable increase in the absorbance extending to the visible-light region between $400-600 \mathrm{~nm}$, which is the typical absorption feature of the nitrogen-doped $\mathrm{TiO}_{2}$.

The photocatalytic activity has been tested by the photodegradation of aqueous solutions of Rhodamine B dye. Figure 9 shows the degradation of RB with time over the Ndoped titania nanotube TC-1 under visible light irradiation. Sample TC- 1 exhibits a remarkable photocatalytic activity than P-25. Over $95 \%$ of the Rhodamine B dye is degraded after $1 \mathrm{~h}$ irradiation for TC- 1 , but only $22 \%$ for P-25 powder. The photocatalytic degradation rate of N-doped TC-1 is far greater than that of P-25 in the first hour. The commercially available P-25 is believed to be a highefficiency photocatalyst due to the synergetic contribution by the mixing phase of anatase and rutile [40]. The extra high photocatalytic efficiency of TC-1 can be interpreted in the view of the high nitrogen content, high surface area, and large mesopore volume. It is noteworthy that the asprepared amorphous TC- 1 shows the highest photocatalytic activity and not the well-crystallized samples TC-1(400). The crystallinity has been reported as the key factor in determining the photoactivity under visible light $[41,42]$. However, our results above point out that the crystallinity

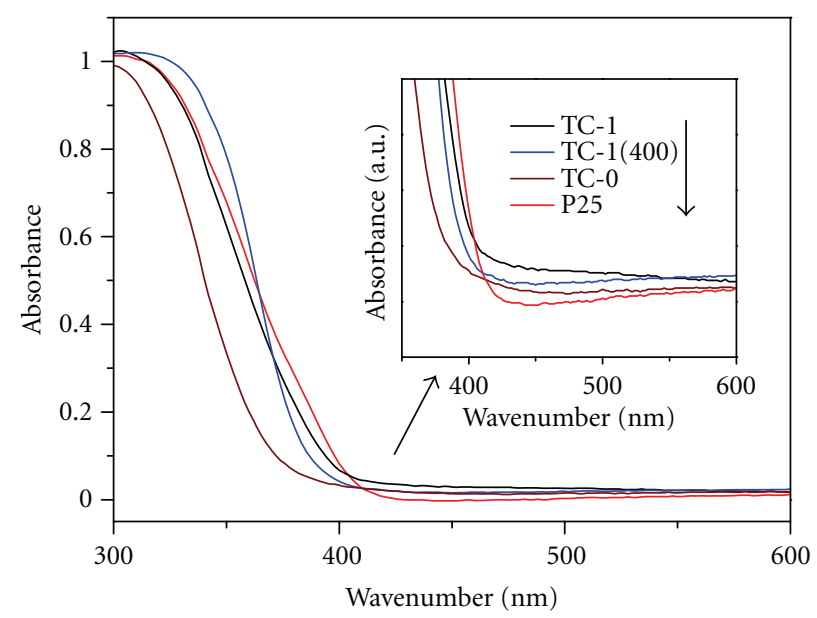

Figure 8: The UV-Vis diffuse reflectance spectra of TC-1, TC1(400), TC-0, and P25.

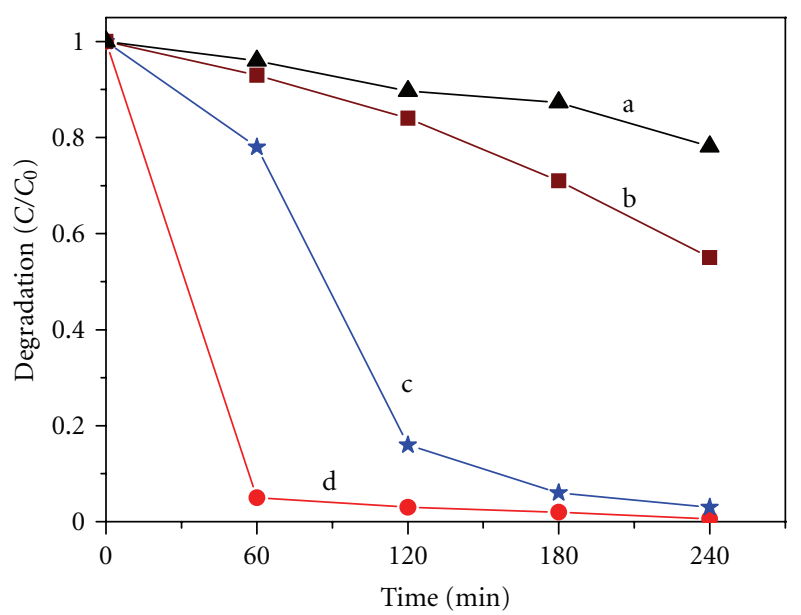

FIGURE 9: Photocatalytic degradation of Rhodamine B under the irradiation of visible light in the presence of (a) TC-0, (b) TC1(400), (c) P25, and (d) TC-1. 
might not be the only factor; the microstructure, nitrogen content, pore volume, and surface area also play influential roles in photoactivity.

It is interesting to point out the photocatalytic activity of P25 under the visible light in Figure 9, since the original P25 does not normally absorb visible light. Two possible reasons can be rationalized. First, according to the manufacture's specification, the UV cutoff filter used in this study can normally screen the irradiation with a wavelength longer than $400 \mathrm{~nm}$ but still has a T50\% at $425 \mathrm{~nm}$. This may account for the mild absorbance of P25 from 420 to $425 \mathrm{~nm}$ in the early stage of irradiation. Similar result has also been reported by Li et al. in 2010 [43]. Second, the cutoff filter effect has also been checked using a spectrometer (HR4000CG, Ocean Optics). It demonstrates a satisfactory screening effect of wavelength less than $400 \mathrm{~nm}$; yet, there is a strong peak from $400 \mathrm{~nm}$, rising to $450 \mathrm{~nm}$ sharply. We believe that this is another reason for the activated P25 within this wavelength region.

The visible light response in nitrogen $\mathrm{N}$-doped $\mathrm{TiO}_{2}$ titania has been extensively investigated but remains under controversy. Chen and Burda reported that the substitutional type nitrogen species with the $\mathrm{N}-\mathrm{O}$ type bonding was responsible for the observed increase in photocatalytic activity in the visible region [36]. Diwald et al. indicated that a binding energy of $399.6 \mathrm{eV}$ for $\mathrm{N}$ 1s was effective in reducing the band gap from 3.0 to $2.4 \mathrm{eV}$, which is a shift of $0.6 \mathrm{eV}$ into the visible spectral region [44]. In general, an $\mathrm{N}$ 1s binding energy near $400 \mathrm{eV}$ is regarded as an active dopant although assignments of its chemical nature differed. Di Valentin et al. investigated the difference in the dopant states for substitutional versus interstitial type impurities in anatase $\mathrm{TiO}_{2}$ by electron paramagnetic resonance spectroscopy and XPS and also by calculations using density functional theory [22]. Very distinct differences in the calculated electronic structure for substitutional versus interstitial type nitrogen were reported. Both types of impurities were found to add localized states within the band gap. For substitutional type nitrogen, these states were located $0.14 \mathrm{eV}$ above the valence band, and for interstitial type nitrogen species (referred to as $\mathrm{N}-\mathrm{O}$ ), the localized states were $0.73 \mathrm{eV}$ above the valence band.

The N1s XPS spectra of TC-1 display a peak at $400.6 \mathrm{eV}$, which can thus be assigned to the interstitial $\mathrm{Ti}-\mathrm{O}-\mathrm{N}$ or $\mathrm{Ti}-\mathrm{N}-\mathrm{O}$ linkages or molecularly chemisorbed $\gamma-\mathrm{N}$ [37]. All these findings lead us to infer that $\mathrm{NH}_{4}{ }^{+}$has successfully incorporated as nitrogen doping source during the formation of $\mathrm{TiO}_{2}$ nanotube and that $\mathrm{N}$-doped $\mathrm{TiO}_{2-x} \mathrm{~N}_{x}$ is transformed into multilayer tubular structure with mesopores which eventually becomes the nanocrystalline anatase, However, the photoactivity of the N-doped nanotube TC-1 decreases, as the calcination temperature increases to $400^{\circ} \mathrm{C}$. This decrease in photoactivity can be explained by the loss of nitrogen content and the destruction of tubular structure, accompanied by a decreased specific area. On the other hand, formation of larger amounts of oxygen vacancies due to high calcination temperatures should be promoted, which further encourages the recombination of photogenerated electron and holes, resulting in a lower photoactivity.

\section{Conclusions}

Nitrogen-doped $\mathrm{TiO}_{2}$ nanotubes were successfully prepared by a simple urea/P25 cohydrothermal method. Morphological study by TEM reveals that the nanotubes change from porous multilayer and tube-shaped structure to dense and aggregated rod-shaped structure when the postannealing temperature increases. Microstructure study by XRD and $\mathrm{BET}$ indicates that the as-prepared $\mathrm{N}$-doped $\mathrm{TiO}_{2}$ nanotube is a lepidocrocite-type sodium titanate compound having a surface area of $292 \mathrm{~m}^{2} / \mathrm{g}$; it changes to the anatase $\mathrm{TiO}_{2}$ after calcination. Chemical identification by XPS shows incorporation of high nitrogen content and the formation of Ti-O-N or Ti-N-O linkages within the nanotubes. Photocatalytic activity experiments indicate that it exhibits high photoactivity under visible light, which is about four times greater than that of P25. The results suggest that the nitrogen content and surface area, rather than crystallinity, are more crucial in determining the photocatalytic activity. We believe that the preparation method of $\mathrm{N}$-doped titanium oxide nanotube derived from this facile cohydrothermal method is simple, costeffective, and environmentally friendly. With further investigation and improvement, it should provide great potential applications in photocatalysis.

\section{References}

[1] S. U. M. Khan, M. Al-Shahry, and W. B. Ingler, "Efficient photochemical water splitting by a chemically modified n$\mathrm{TiO}_{2}$," Science, vol. 297, no. 5590, pp. 2243-2245, 2002.

[2] R. Asahi, T. Morikawa, T. Ohwaki, K. Aoki, and Y. Taga, "Visible-light photocatalysis in nitrogen-doped titanium oxides," Science, vol. 293, no. 5528, pp. 269-271, 2001.

[3] H. Kisch, S. Sakthivel, M. Janczarek, and D. Mitoraj, "A LowBand gap, nitrogen-modified titania visible-light photocatalyst," Journal of Physical Chemistry C, vol. 111, no. 30, pp. 11445-11449, 2007.

[4] J. C. Yu, J. Yu, W. Ho, Z. Jiang, and L. Zhang, "Effects of Fdoping on the photocatalytic activity and microstructures of nanocrystalline $\mathrm{TiO}_{2}$ powders," Chemistry of Materials, vol. 14, no. 9, pp. 3808-3816, 2002.

[5] J. Lukáč, M. Klementová, P. Bezdička et al., "Characterization of $\mathrm{Zr}$-doped $\mathrm{TiO} 2$ prepared by homogenous co-precipitation without high-temperature treatment," Journal of Materials Science, vol. 42, no. 22, pp. 9421-9428, 2007.

[6] W. Choi, A. Termin, and M. R. Hoffmann, "The role of metal ion dopants in quantum-sized $\mathrm{TiO}_{2}$ : correlation between photoreactivity and charge carrier recombination dynamics," Journal of Physical Chemistry, vol. 98, no. 51, pp. 13669-13679, 1994.

[7] M. Zhou, J. Yu, and B. Cheng, "Effects of Fe-doping on the photocatalytic activity of mesoporous $\mathrm{TiO}_{2}$ powders prepared by an ultrasonic method," Journal of Hazardous Materials, vol. 137, no. 3, pp. 1838-1847, 2006.

[8] M. A. Henderson, J. M. White, H. Uetsuka, and H. Onishi, "Photochemical charge transfer and trapping at the interface between an organic adlayer and an oxide semiconductor," Journal of the American Chemical Society, vol. 125, no. 49, pp. 14974-14975, 2003.

[9] J. Y. Lee, J. Park, and J. H. Cho, "Electronic properties of N-and C-doped $\mathrm{TiO}_{2}$," Applied Physics Letters, vol. 87, no. 1, Article ID 011904, 2005. 
[10] D. Chen, D. Yang, Q. Wang, and Z. Jiang, "Effects of boron doping on photocatalytic activity and microstructure of titanium dioxide nanoparticles," Industrial and Engineering Chemistry Research, vol. 45, no. 12, pp. 4110-4116, 2006.

[11] T. Ohno, T. Mitsui, and M. Matsumura, "Photocatalytic activity of S-doped $\mathrm{TiO}_{2}$ photocatalyst under visible light," Chemistry Letters, vol. 32, no. 4, pp. 364-365, 2003.

[12] T. Kasuga, M. Hiramatsu, A. Hoson, T. Sekino, and K. Niihara, "Titania nanotubes prepared by chemical processing," Advanced Materials, vol. 11, no. 15, pp. 1307-1311, 1999.

[13] T. Kasuga, M. Hiramatsu, A. Hoson, T. Sekino, and K. Niihara, "Formation of titanium oxide nanotube," Langmuir, vol. 14, no. 12, pp. 3160-3163, 1998.

[14] B. D. Yao, Y. F. Chan, X. Y. Zhang, W. F. Zhang, Z. Y. Yang, and N. Wang, "Formation mechanism of $\mathrm{TiO}_{2}$ nanotubes," Applied Physics Letters, vol. 82, no. 2, pp. 281-283, 2003.

[15] D. V. Bavykin, S. N. Gordeev, A. V. Moskalenko, A. A. Lapkin, and F. C. Walsh, "Apparent two-dimensional behavior of $\mathrm{TiO}_{2}$ nanotubes revealed by light absorption and luminescence," Journal of Physical Chemistry B, vol. 109, no. 18, pp. 85658569, 2005.

[16] M. Paulose, K. Shankar, O. K. Varghese, G. K. Mor, and C. A. Grimes, "Application of highly-ordered $\mathrm{TiO}_{2}$ nanotube-arrays in heterojunction dye-sensitized solar cells," Journal of Physics D, vol. 39, no. 12, pp. 2498-2503, 2006.

[17] S. Yin, K. Ihara, M. Komatsu et al., "Low temperature synthesis of $\mathrm{TiO}_{2}-\mathrm{xNy}$ powders and films with visible light responsive photocatalytic activity," Solid State Communications, vol. 137, no. 3, pp. 132-137, 2006.

[18] G. R. Torres, T. Lindgren, J. Lu, C. G. Granqvist, and S. E. Lindquist, "Photoelectrochemical study of nitrogen-doped titanium dioxide for water oxidation," Journal of Physical Chemistry B, vol. 108, no. 19, pp. 5995-6003, 2004.

[19] P. G. Wu, C. H. Ma, and J. K. Shang, "Effects of nitrogen doping on optical properties of $\mathrm{TiO}_{2}$ thin films," Applied Physics A, vol. 81, no. 7, pp. 1411-1417, 2005.

[20] F. Fabreguette, L. Imhoff, M. Maglione et al., "Correlation between the electrical properties and morphology of lowpressure MOCVD titanium oxynitride thin films grown at various temperatures," Chemical Vapor Deposition, vol. 6, no. 3, pp. 109-114, 2000.

[21] J. L. Gole, J. D. Stout, C. Burda, Y. Lou, and X. Chen, "Highly efficient formation of visible light tunable $\mathrm{TiO}_{2}-\mathrm{xNx}$ photocatalysts and their transformation at the nanoscale," Journal of Physical Chemistry B, vol. 108, no. 4, pp. 1230-1240, 2004.

[22] C. Di Valentin, G. Pacchioni, A. Selloni, S. Livraghi, and E. Giamello, "Characterization of paramagnetic species in $\mathrm{N}$-doped $\mathrm{TiO}_{2}$ powders by EPR spectroscopy and DFT calculations," Journal of Physical Chemistry B, vol. 109, no. 23, pp. 11414-11419, 2005.

[23] A. Ghicov, J. M. Macak, H. Tsuchiya et al., "Ion implantation and annealing for an efficient $\mathrm{N}$-doping of $\mathrm{TiO}_{2}$ nanotubes," Nano Letters, vol. 6, no. 5, pp. 1080-1082, 2006.

[24] A. Ghicov, J. M. Macak, H. Tsuchiya et al., " $\mathrm{TiO}_{2}$ nanotube layers: dose effects during nitrogen doping by ion implantation," Chemical Physics Letters, vol. 419, no. 4-6, pp. 426-429, 2006.

[25] Q. Chen, W. Zhou, G. H. Du, and L. M. Peng, "Trititanate nanotubes made via a single alkali treatment," Advanced Materials, vol. 14, no. 17, pp. 1208-1211, 2002.

[26] Y. Lan, X. Gao, H. Zhu et al., "Titanate nanotubes and nanorods prepared from rutile powder," Advanced Functional Materials, vol. 15, no. 8, pp. 1310-1318, 2005.
[27] R. Yoshida, Y. Suzuki, and S. Yoshikawa, "Effects of synthetic conditions and heat-treatment on the structure of partially ion-exchanged titanate nanotubes," Materials Chemistry and Physics, vol. 91, no. 2-3, pp. 409-416, 2005.

[28] R. Ma, Y. Bando, and T. Sasaki, "Nanotubes of lepidocrocite titanates," Chemical Physics Letters, vol. 380, no. 5-6, pp. 577582, 2003.

[29] L. Q. Weng, S. H. Song, S. Hodgson, A. Baker, and J. Yu, "Synthesis and characterisation of nanotubular titanates and titania," Journal of the European Ceramic Society, vol. 26, no. 8, pp. 1405-1409, 2006.

[30] J. Yu, H. Yu, B. Cheng, X. Zhao, and Q. Zhang, "Preparation and photocatalytic activity of mesoporous anatase $\mathrm{TiO}_{2}$ nanofibers by a hydrothermal method," Journal of Photochemistry and Photobiology A, vol. 182, no. 2, pp. 121-127, 2006.

[31] F. Peng, L. Cai, H. Yu, H. Wang, and J. Yang, "Synthesis and characterization of substitutional and interstitial nitrogendoped titanium dioxides with visible light photocatalytic activity," Journal of Solid State Chemistry, vol. 181, no. 1, pp. 130-136, 2008.

[32] K. S. W. Sing, D. H. Everett, R. A. W. Haul, L. Moscou, R. A. Pierotti, J. Rouquerol et al., "Reporting physisorption data for gas/solid systems with special reference to the determination of surface area and porosity," Pure and Applied Chemistry, vol. 57, no. 4, pp. 603-619, 1985.

[33] R. Nakamura, T. Tanaka, and Y. Nakato, "Mechanism for visible light responses in anodic photocurrents at $\mathrm{N}$-doped $\mathrm{TiO}_{2}$ film electrodes," Journal of Physical Chemistry B, vol. 108, no. 30, pp. 10617-10620, 2004.

[34] M. Sathish, B. Viswanathan, R. P. Viswanath, and C. S. Gopinath, "Synthesis, characterization, electronic structure, and photocatalytic activity of nitrogen-doped $\mathrm{TiO}_{2}$ nanocatalyst," Chemistry of Materials, vol. 17, no. 25, pp. 6349-6353, 2005.

[35] S. Sakthivel, M. Janczarek, and H. Kisch, "Visible light activity and photoelectrochemical properties of nitrogen-doped $\mathrm{TiO}_{2}$," Journal of Physical Chemistry B, vol. 108, no. 50, pp. 19384-19387, 2004.

[36] X. Chen and C. Burda, "Photoelectron spectroscopic investigation of nitrogen-doped titania nanoparticles," Journal of Physical Chemistry B, vol. 108, no. 40, pp. 15446-15449, 2004.

[37] N. C. Saha and H. G. Tompkins, "Titanium nitride oxidation chemistry: an x-ray photoelectron spectroscopy study," Journal of Applied Physics, vol. 72, no. 7, pp. 3072-3079, 1992.

[38] W. H. R. Shaw and J. J. Bordeaux, "The decomposition of urea in aqueous media," Journal of the American Chemical Society, vol. 77, no. 18, pp. 4729-4733, 1955.

[39] Y. Cong, J. Zhang, F. Chen, and M. Anpo, "Synthesis and characterization of nitrogen-doped $\mathrm{TiO}_{2}$ nanophotocatalyst with high visible light activity," Journal of Physical Chemistry C, vol. 111, no. 19, pp. 6976-6982, 2007.

[40] T. Ohno, K. Sarukawa, K. Tokieda, and M. Matsumura, "Morphology of a $\mathrm{TiO}_{2}$ photocatalyst (Degussa, P-25) consisting of anatase and rutile crystalline phases," Journal of Catalysis, vol. 203, no. 1, pp. 82-86, 2001.

[41] S. Yin, J. Wu, M. Aki, and T. Sato, "Photocatalytic hydrogen evolution with fibrous titania prepared by the solvothermal reactions of protonic layered tetratitanate $\left(\mathrm{H}_{2} \mathrm{Ti}_{4} \mathrm{O}_{9}\right)$," International Journal of Inorganic Materials, vol. 2, no. 4, pp. 325331, 2000.

[42] S. Yin, Y. Aita, M. Komatsu, and T. Sato, "Visible-light-induced photocatalytic activity of $\mathrm{TiO}_{2-x} \mathrm{~N}_{y}$ prepared by solvothermal process in urea-alcohol system," Journal of the European Ceramic Society, vol. 26, no. 13, pp. 2735-2742, 2006. 
[43] G. Li, G. Song, J. Chen, M. Zhu, and P. K. Wong, "Photocatalytic degradation of methylene blue by magnetically separable $\mathrm{BiVO} 4$ supported on $\mathrm{Fe}_{3} \mathrm{O}_{3}$ nanoparticles," in Proceedings of the 2nd Conference on Environmental Science and Information Application Technology, pp. 352-355, IEEE, July 2010.

[44] O. Diwald, T. L. Thompson, T. Zubkov, E. G. Goralski, S. D. Walck, and J. T. Yates, "Photochemical activity of nitrogendoped rutile $\mathrm{TiO}_{2}(110)$ in visible light," Journal of Physical Chemistry B, vol. 108, no. 19, pp. 6004-6008, 2004. 


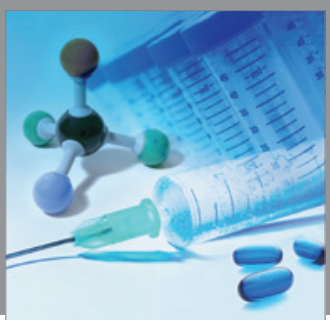

International Journal of

Medicinal Chemistry

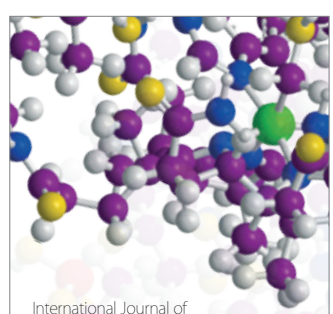

Carbohydrate Chemistry

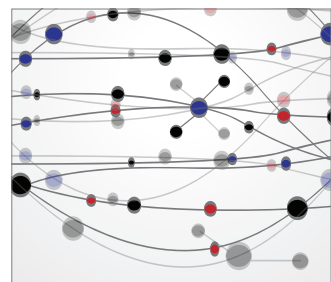

The Scientific World Journal
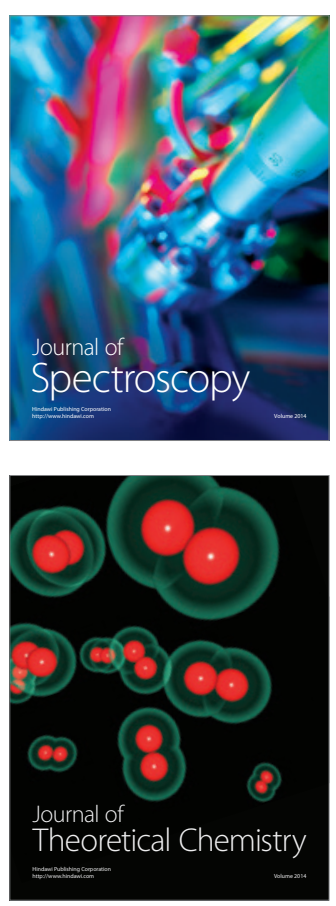
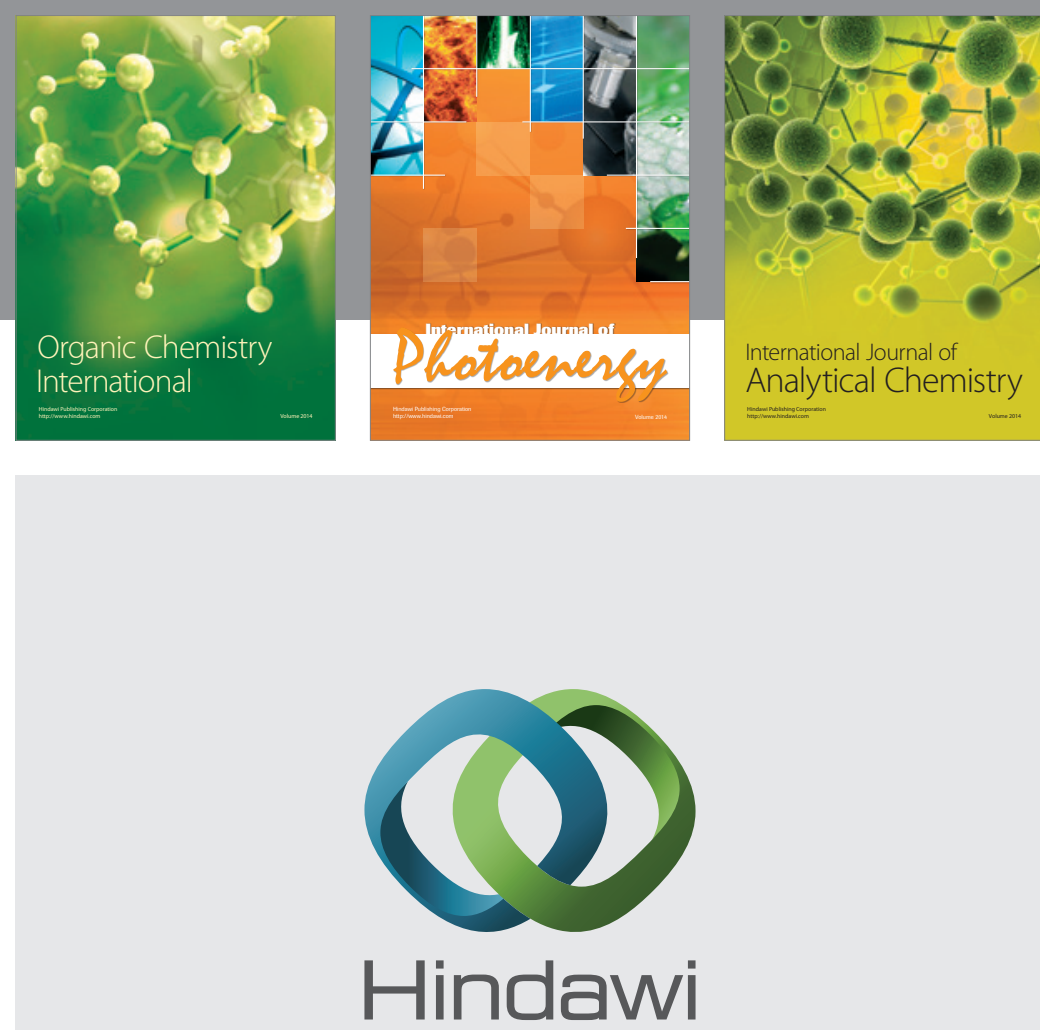

Submit your manuscripts at

http://www.hindawi.com
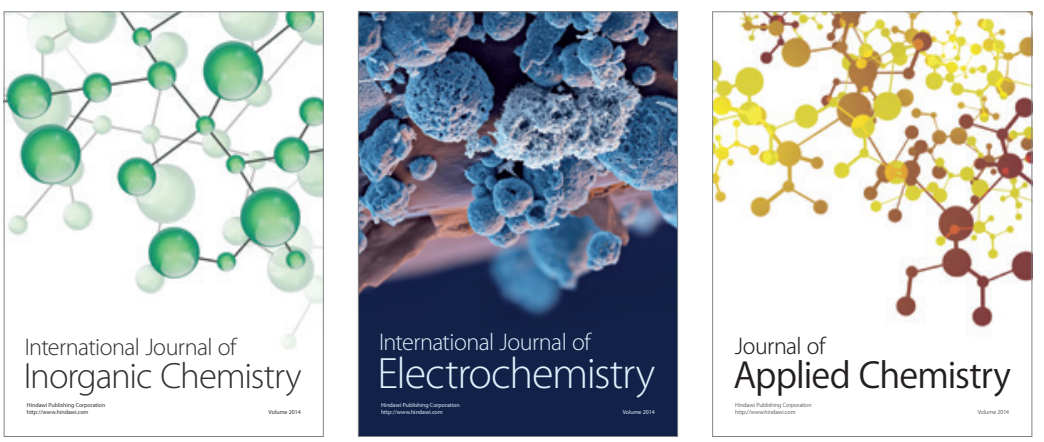

Journal of

Applied Chemistry
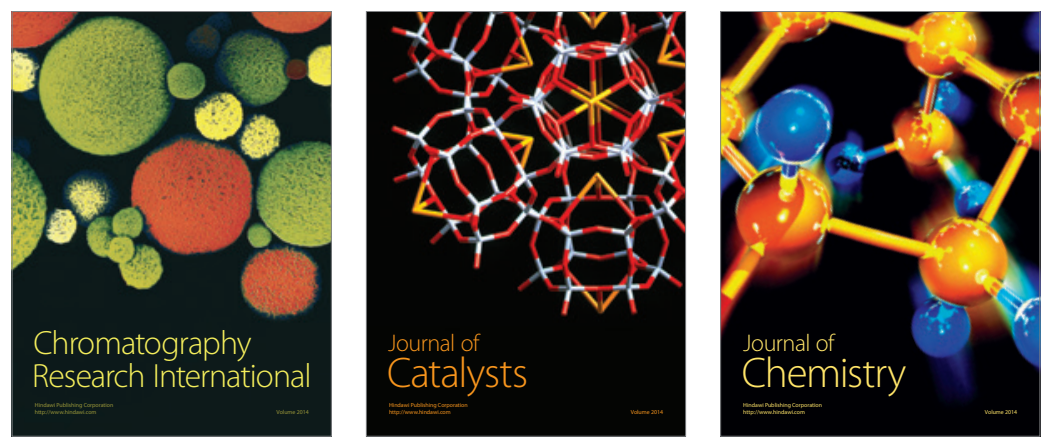
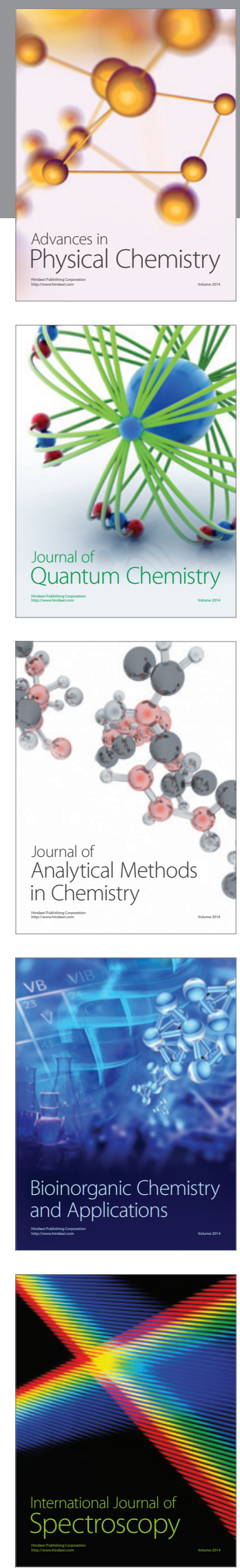